present cartoons which show how as a profession we are able to take a joke against ourselves.

Could members consider sending me their own favourite cartoons gleaned from the media? It would be most helpful if dates and sources could be included to help in seeking copyright permission.

Department of Psychiatry of Old Age

St Martin's Hospital

Midford Road

Bath, Avon BA2 5RP
Alan MoOre

\section{$S R$ posts and publications}

\section{DeAR Sirs}

As a (first rate) post-membership registrar in an intensely busy post I have little enough time to put together an SR application let alone 'publish' for it. Hence this letter. Many thanks.

Mental Health Unit

Peter McColl Chesterfield \& North Derbyshire Royal Hospital Chesterfield S44 5BL

\title{
European Association for the History of Psychiatry
}

The European Association for the History of Psychiatry is holding its triennial conference from 17 to 20 August 1993 at Friends House, 173-177 Euston Road, London NW1. Plenary sessions will be held on the historiography of psychiatry and the epistemology of psychiatry. There will be parallel sessions and workshops on specific aspects of the history of psychiatry in its widest sense: therapeutics, forensic psychiatry, the asylum, psychoanalysis, psychiatry and religion, diagnostics, feminism and psychiatry, etc. Visits have been arranged to the Freud Museum and the Bethlem Museum and Archives. Films on the history of psychiatry will be shown. The registration fee is $£ 70$. Daily rates are available.

Please write for a copy of the programme and a registration form to Frieda Houser, Wellcome Institute for the History of Medicine, 183 Euston Road, London NW1 2BE.
A conference Community Treatment of Personality Disorder-Creative Solutions will be held on 24 September 1993 at the National Water Sports Centre, Nottingham. Further information: The
Conference Organiser, c/o Hostels Liaison Group, 23 Mansfield Road, Nottingham NG1 3FB (telephone 0602 473404; fax 0602859551 ). 